\title{
Premature Termination of Treatment among Adults Attending Treatment for Eating Disorders: A Critical Review
}

\author{
Flávia Machado Seidinger-Leibovitz ${ }^{1}{ }^{\circledR}$, Adams Rodrigues Malta1, Larissa Rodrigues ${ }^{1,2}$, \\ Rodrigo Almeida Bastos ${ }^{1,2}$, Pedro Augusto Thiene Leme ${ }^{3}$, Daniela Ferreira Araújo Silva4, \\ Egberto Ribeiro Turato ${ }^{1}$, Carla Maria Vieira ${ }^{5}$
}

\footnotetext{
${ }^{1}$ Department of Medical Psychology and Psychiatry, School of Medical Sciences, State University of Campinas, Campinas, Brazil ${ }^{2}$ Department of Obstetrics and Gynecology, School of Medical Sciences, State University of Campinas, Campinas, Brazil ${ }^{3}$ Department of Health Sciences and Pediatric Dentistry, Piracicaba Dental School, State University of Campinas, Piracicaba, Brazil

${ }^{4}$ Federal University of São Paulo, Department of Preventive Medicine, São Paulo, Brazil

${ }^{5}$ Science and Technology Center in Sovereignty and Food Security/Institute of Bioscience, São Paulo State University (UNESP), Botucatu, São Paulo, Brazil

Email: flaviamsleibovitz@gmail.com
}

\begin{abstract}
How to cite this paper: Seidinger-Leibovitz, F.M., Malta, A.R., Rodrigues, L., Bastos, R.A., Leme, P.A.T., Silva, D.F.A., Turato, E.R. and Vieira, C.M. (2020) Premature Termination of Treatment among Adults Attending Treatment for Eating Disorders: A Critical Review. Open Journal of Medical Psychology, 9, 123-140. https://doi.org/10.4236/ojmp.2020.93010
\end{abstract}

Received: May 12, 2020

Accepted: July 20, 2020

Published: July 23, 2020

Copyright $\odot 2020$ by author(s) and Scientific Research Publishing Inc. This work is licensed under the Creative Commons Attribution International License (CC BY 4.0).

http://creativecommons.org/licenses/by/4.0/ (c) (i) Open Access

\begin{abstract}
The article presents a critical review regarding the premature termination of eating disorder's treatment among inpatients and outpatients, with the aim of identifying-emotional, psychodynamic and family-related aspects involved. The search strategy used the following MeSH terms combined by Boolean operators: "eating disorders" AND "treatment" OR "patient dropouts" OR "drop-out/dropouts" OR "attrition" OR "premature termination" AND "empirical study" OR "qualitative research", for on Medline/PUBMED, PsycINFO and EMBASE databases. This article follows the PRISMA Guidelines. A total of 26 studies composed this review, of which 24 were original research articles, 1 was a review and 1 a theoretical article. Only two articles applied qualitative methods analyzing categories of content obtained by in-depth interviews, three combine quantitative and qualitative methods and other three present qualitative analyses while discussing quantitative studies. Further qualitative studies should be carried out to clarify meanings of dropout, premature termination of treatment, and attrition. Different expectations held by patients and by therapeutic teams, and the interpersonal difficulties of these types of patients, stand out as difficulties in constructing "therapeutic alliances", with impacts on dropout, premature termination and attrition rates.
\end{abstract}




\section{Keywords}

Eating Disorders, Adults, Patient Dropouts, Attrition, Premature Termination of Treatment, Inpatients, Outpatients

\section{Introduction}

The landmark research study on dropout (DO) for eating disorders (ED) was published in 1983 [1]. This phenomenon is described as a complex and multifaceted reality that challenges clinicians and researchers. During the following decades, research on the subject has evolved, especially regarding methodology, benefiting from both theoretical and review studies.

This review discusses some concepts in Eating Disorders field, methodological advances and changes that have occurred in the use of terms over the last decade. Our search included all types of ED in adults undergoing inpatient or outpatient treatment. One immediate question was the term "dropout" itself and the biases regarding its use [2] [3] [4]. In order to simplify the question of vocabulary, this review examines advances in research that focus on patient dropout, more technically termed "Premature Termination of Treatment" (PTT), to avoid the biases around the term DO noted by Sly [2], Campbell [3] and Wallier [4].

Beginning with the reviews published in the first decade of this century concerning inpatients [4] and outpatients [5], respectively, very important issues called for further research and are considered here. One pertinent question, at this point, is therefore: What should be considered new since the issues of bias over the term "dropout" and over methods to be used were first highlighted regarding each modality of treatment.

In a viewpoint article in 2009, Campbell [3] expressed concern over the rise in ED-related DO rates, which more than doubled over a period of 16 years. To retain participants in ED research trials was proven to be a major challenge, and probably an even greater issue in standard clinical settings. In this regard, we might recall the remark "We are just getting worse at the job" [3]. In view of this scenario, a new review seemed pertinent.

\section{Method}

The authors reviewed studies focused on processes of premature termination of treatment (PTT), DO and attrition by inpatient and outpatient adults in treatment for ED. The guiding question was formulated on the bases of conclusions drawn from an earlier literature review on the subject [6]: "What factors are involved in the complex phenomenon of PPT-taking into account emotional, psychodynamic and family-related aspects-among patients engaged in treatment programs?". We define "premature termination of treatment"-and its synonyms DO and attrition-as discontinuation of treatment by a patient without the team's prior consent, as opposed to unilateral discharge by the treatment team. 
A search strategy was then carried out on the EMBASE, PsycInfo/APA and Medline/PUBMED databases, using the following MeSH terms combined by Boolean operators: "eating disorders" AND "treatment" OR "patient dropouts" OR "drop-out/dropouts" OR "attrition" OR "premature termination" AND "empirical study" OR "qualitative research", for on Medline/PUBMED, EMBASE and PsycINFO databases. The search was conducted in February, 2016, and no specification of a timeframe neither a language filter was determined, in order to allow a broad search corresponding to the critical nature of this review. The aim was to go beyond evaluating objective results, and reveal contradictions, thus enabling a discussion of issues and progress in the area, including both research and clinical practice. The search resulted in 76 articles-seven of which showed up in more than one database, giving a total of 83 finds.

All 76 articles were then screened by reading the abstracts and judged according to the following inclusion criteria: studies which 1) focused on the topic of PTT, DO or attrition from treatment for ED; 2) dealt with samples comprised solely of adults (16 y.o. and over); 3 ) indicated the application of a consistent and clearly described method that would enable replication; 4) contained a consistent discussion on the topic and possibly served as a pertinent contribution to answering the guiding question cited above. Forty articles were then excluded. Of the 36 remaining, only five were written in languages other than English (two in German, one in Italian, one in Polish and one in Icelandic, and all these had been translated into English). These 36 studies were read in full, summarized and evaluated by the authors on the bases of the same inclusion criteria listed above. During this stage, ten further articles were excluded for different reasons: one for showing an inconsistent method, three for failing to focus on the central topic, two for failing to focus on ED, two for including adolescents in the sample and two for unreliable translation (those in Polish and Icelandic).

The articles were summarized and theme units were identified and selected according to qualitative saturation criteria and their relevance to the guiding question. The flowchart (Figure 1) below describes the search.

\section{Results}

The final 26 studies included one literature review [4], one viewpoint article [3] and 24 original research articles, only two of which were qualitative in nature analyzing categories of content obtained by in-depth interviews [7] [8]; and three described mixed-methods research [9] [10] [11]. The following Table 1 summarizes the characteristics and results of each of the studies included in the current review.

Treatment regimen: From a total of 26 articles, except the viewpoint article mention the regimen, we found a balanced distribution of studies focused on both treatment modalities: 12 inpatient [4] [9] [11]-[20] and 12 outpatient service [7] [8] [10] [21] [22] [23] [24] [25] and one analyzes both [26].

Diagnosis: Many (14) of the studies analyzed focus on ED in general, in 


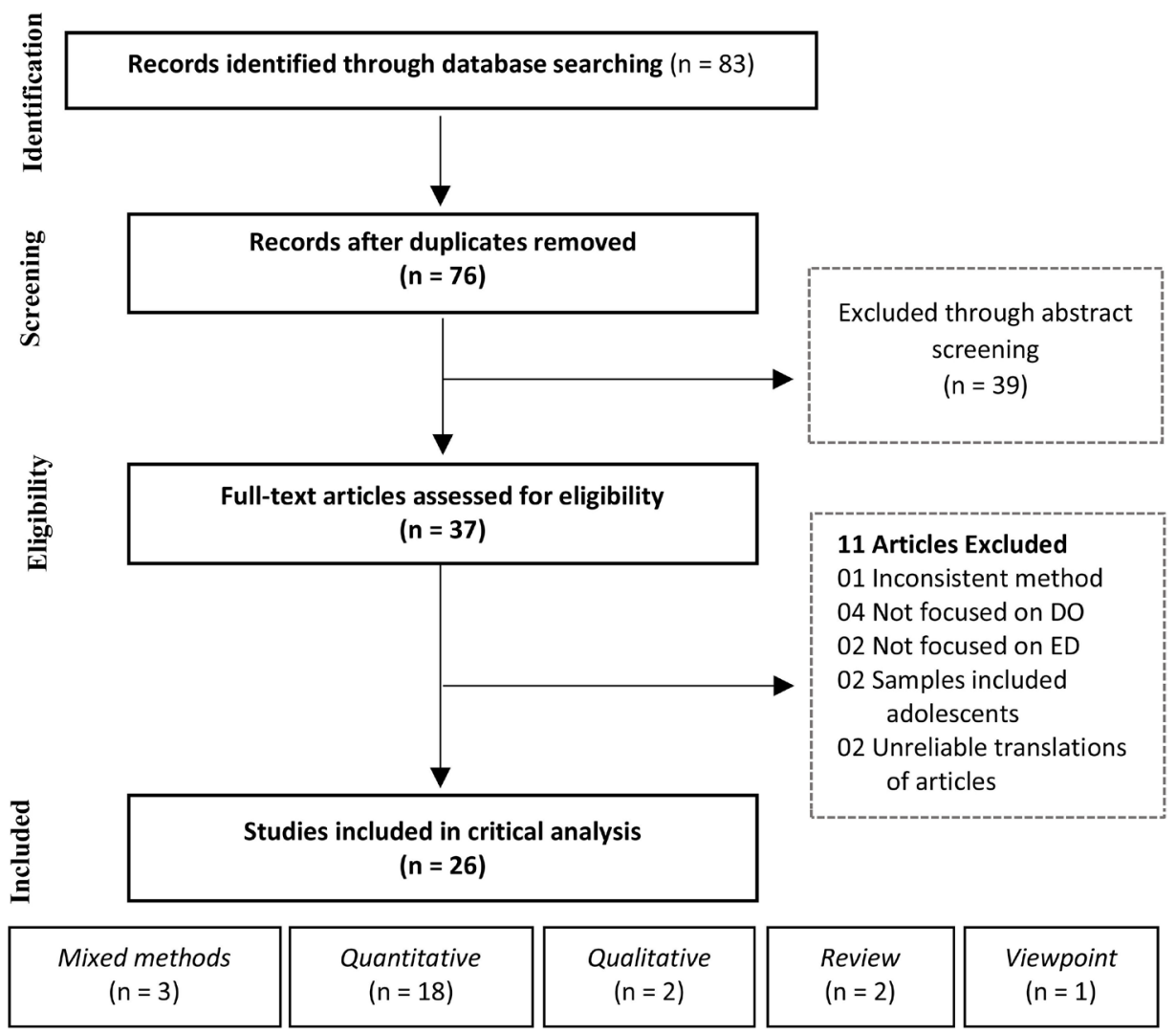

Figure 1. PRISMA flow diagram.

different combinations of diagnosis and subtypes; followed by seven studies on Anorexia Nervosa (AN) [4] [9] [10] [12] [13] [14] [15]. Two studies [21] [27] analyze BN and BN atypical, and one analyzes Eating Disorders Not Otherwise Specified (EDNOS) and BN [28]. The diagnostic criteria considered include DSM IIITR, DSM IV, DSM IV-TR. One review article [4] includes studies that apply DSM-IV, ICD-10 and Feighner criteria. Stein, Wing, Lewis \& Raghunatha [29] adopt Strober plus DSM-IV EDNOS criteria to include sub-threshold AN and BN. Two studies [21] [30] explicitly exclude binge-eating disordered patients. A few studies fail to specify the diagnostic criteria adopted [8] [22] [28]. But it is interesting to note that EDNOS was increasingly included as a criterion beginning in 2005 with a notable concentration of EDNOS in later years, especially between 2010 and 2014. There seems to have been a tendency to target ED in general, including EDNOS, in more recent years. This is important because EDNOS has been notably under-studied. One should also recall that these displacements were also determined by changes in statistical and diagnostic manuals during this period. It is also important to recall that establishing diagnostic criteria in ED is a major issue, including in research.

Method: A tendency toward greater method accuracy can be noted in more recent years. Instruments of measurement have become more and more complex, as have the growing number of studies using logistic regression, in contrast to the limited number of qualitative studies. The great majority, 18 out of 26 
Table 1. Characteristics and results of studies included in the synthesis.

\begin{tabular}{|c|c|c|c|c|c|c|}
\hline $\begin{array}{l}\text { Author/ } \\
\text { Year/ } \\
\text { Country }\end{array}$ & Focus & Method & Conclusion & $\begin{array}{l}\text { Diagnostic } \\
\text { inclusion } \\
\text { criteria }\end{array}$ & $N=$ & $\begin{array}{l}\text { Treatment } \\
\text { Regimen }\end{array}$ \\
\hline $\begin{array}{l}\text { Clinton, } \\
1996[20] \\
\text { Sweden }\end{array}$ & $\begin{array}{l}\text { Role of patient-therapist } \\
\text { relationship and other } \\
\text { variables for DO by ED } \\
\text { patients. }\end{array}$ & Quantitative & $\begin{array}{l}\text { DO by ED patients is related to the } \\
\text { patient-therapist relationship; Therapists should } \\
\text { discuss patients' expectations of treatment from } \\
\text { the outset and focus on particular areas of } \\
\text { discrepancy. }\end{array}$ & $\begin{array}{l}\text { AN, BN, } \\
\text { atypical ED } \\
\text { _DSM III-R }\end{array}$ & 60 & Inpatient \\
\hline $\begin{array}{l}\text { Zeeck \& } \\
\text { Herzog, } 2000 \\
{[12]} \\
\text { Germany }\end{array}$ & $\begin{array}{l}\text { Prospective study searching } \\
\text { for predictors of DO. }\end{array}$ & Quantitative & $\begin{array}{l}\text { Form of termination of treatment should be } \\
\text { routinely assessed. Previous DO and comorbidity } \\
\text { are indicators of DO risk. }\end{array}$ & AN_ICD-10 & 80 & Inpatient \\
\hline $\begin{array}{l}\text { Mahon et al., } \\
2001[21] \\
\text { United } \\
\text { Kingdom }\end{array}$ & $\begin{array}{l}\text { Retrospective study } \\
\text { searching for pre-treatment } \\
\text { factors predicting DO in BN } \\
\text { and atypical BN outpatients. }\end{array}$ & Quantitative & $\begin{array}{l}\text { Witnessing parental breakup, being younger, } \\
\text { being employed outside the home, and having } \\
\text { previous experience of psychiatric treatment } \\
\text { predicted DO. Experiences of childhood } \\
\text { trauma had a dose-effect relationship with DO. } \\
\text { An impaired ability to trust resulting from } \\
\text { disturbed attachments may link childhood trauma } \\
\text { and dropping out. }\end{array}$ & $\begin{array}{l}\text { BN, } \\
\text { atypical BN } \\
\text { ICD-10 }\end{array}$ & 111 & Outpatient \\
\hline $\begin{array}{l}\text { Fassino et al., } \\
2003 \text { [27] } \\
\text { Italy }\end{array}$ & $\begin{array}{l}\text { Exploring personality, } \\
\text { psychopathology and } \\
\text { clinical features of bulimic } \\
\text { patients who do not } \\
\text { complete psychotherapy. }\end{array}$ & Quantitative & $\begin{array}{l}\text { Profile of bulimic patients who dropped out from } \\
\text { brief psychotherapy: they are less cooperative and } \\
\text { more predisposed to anger, suggesting that } \\
\text { dropping out in a subgroup of Bulimic patients } \\
\text { could be related to borderline personality traits } \\
\text { and to difficulties to maintain a therapeutic } \\
\text { relationship. }\end{array}$ & BN_DSM IV & 86 & Outpatient \\
\hline $\begin{array}{l}\text { Surgenor et } \\
\text { al., } 2004 \text { [9] } \\
\text { New Zealand }\end{array}$ & $\begin{array}{l}\text { Whether the risk of } \\
\text { treatment drop-out can be } \\
\text { determined by information } \\
\text { routinely collected at } \\
\text { admission. }\end{array}$ & $\begin{array}{l}\text { Mixed } \\
\text { Methods }\end{array}$ & $\begin{array}{l}\text { Few variables commonly collated by clinicians } \\
\text { contribute to identify patients likely to DO. }\end{array}$ & AN_DSM IV & 213 & Inpatient \\
\hline $\begin{array}{l}\text { Zeeck et al., } \\
2005[13] \\
\text { Germany }\end{array}$ & $\begin{array}{l}\text { Identifying patient } \\
\text { characteristics that } \\
\text { distinguish dropouts from } \\
\text { completers of in-patient } \\
\text { treatment for AN. }\end{array}$ & Quantitative & $\begin{array}{l}\text { Addressing the high ambivalence and maturity } \\
\text { fears of anorexic patients should be an essential } \\
\text { issue in psychotherapy with this patient group. }\end{array}$ & $\begin{array}{l}\text { AN restrictive } \\
\text { and } \\
\text { purging } \\
\text { subtypes } \\
\text { _DSM } \\
\text { IV/ICD-10 }\end{array}$ & 133 & Inpatient \\
\hline $\begin{array}{l}\text { Peake et al., } \\
2005[22] \\
\text { United } \\
\text { Kingdom }\end{array}$ & $\begin{array}{l}\text { Factors associated with } \\
\text { dropping out of treatment at } \\
\text { the Oxford Adult Eating } \\
\text { Disorders Service. }\end{array}$ & Quantitative & $\begin{array}{l}\text { Higher levels of depressive symptoms and } \\
\text { cognitions, and the characteristic of impulsivity } \\
\text { were related to DO. Identifying those patients and } \\
\text { adopting an individually adapted treatment } \\
\text { approach may reduce their ambivalence towards } \\
\text { engaging in treatment. }\end{array}$ & $\begin{array}{l}\text { It doesn't } \\
\text { mention } \\
\text { diagnostic } \\
\text { criteria. }\end{array}$ & 261 & Outpatient \\
\hline $\begin{array}{l}\text { Swan-Kremei } \\
\text { et al., } \\
2005[28] \\
\text { USA }\end{array}$ & $\begin{array}{l}\text { Impact, on treatment } \\
\text { attrition, of the distance } \\
\text { traveled for treatment. }\end{array}$ & Quantitative & $\begin{array}{l}\text { The higher DO rate in employed subjects suggests } \\
\text { possible work conflicts. It is possible that subjects } \\
\text { who live further away do not consider coming } \\
\text { unless their motivation is high, whereas those less } \\
\text { motivated do not even call. }\end{array}$ & $\begin{array}{l}\mathrm{BN}, \mathrm{AN}, \\
\text { EDNOS No } \\
\text { reference to } \\
\text { source of } \\
\text { diagnostic } \\
\text { criteria. }\end{array}$ & 209 & Outpatient \\
\hline
\end{tabular}




\section{Continued}

Zanetti et al., Dropping out in a sample of Mixed 2005 [10] anorexic patients and the Methods Italy evolution of those within the sample who abandoned treatment.
Variables related to the severity of the disease are not a predictive factor for dropping out, whereas clinical features such as depressive symptoms, hostility and presence of self-injurious compulsive behavior were quite important. Initial response to treatment seems to lead to a favorable medium-term prognosis among patients who abandoned therapy.

Bandini et al., Dropping out by EDed 2006 [25] patients from outpatient Italy cognitive-behavioral therapy.

Masson et al., Rates, timing and predictors Quantitative 'Tin 2007 [19] of patient who DO and are Canada administrative discharged. was due to ED or DO. Presence of DSM Axis-I comorbidity was the only factor related to risk of
Quantitative DO from ED treatment was affected primarily by AN, BN, factors which were related to patients' attitude and EDNOS behavior. Therefore, these factors should be carefully addressed in patients with ED to improve participation in treatment and outcome.

_DSM IV
AN_DSM IV 163 Outpatient

Outpatient

AN, BN, 186 Inpatient AD. No factors were predictive of patients dropping out of treatment. The findings support the notion that $\mathrm{AD}$ and patient $\mathrm{DO}$ are different events that may have different factors influencing their rates and timing.

Wallier et al., Critical review of studies on Review 2009 [4] DO from inpatient France treatment for AN.
EDNOS

_DSM IV
Inpatient
Studies often don't distinguish between staff and patient initiated DO and research should analyze both categories separately. Multi-center studies and larger samples reduce biases. Weight on admission, AN subtype and the absence of depression appear to be related to DO from inpatient care.
AN_DSM IV,

DSM-IV+

ICD-10,

Feighner
$\mathrm{AN}, \mathrm{BN}$,

Inpatient such as defiance against those who force them into EDNOS treatment, a lack of confidence in making DSM-IV therapeutic changes, or because the treatment program does not meet the patients' needs or expectations. Provision of choice within treatment may reduce rebellious DO.

Quantitative The presence of the narcissistically abused personality defense style was associated with a higher likelihood of DO of outpatient CBT, thus reducing their access to evidence-based care. United from the early stage of CBT

Campbell et $\quad$ The relationship between
al., 2009 [23] narcissism and drop-out Kingdom for ED.

Campbell, 2009 [3]

Difficulties that drop-out poses to clinicians and

United researchers.

Kingdom

Bjork et al., 2009 [26]

Examining clinical status of Sweden ED patients 36 months after admission.

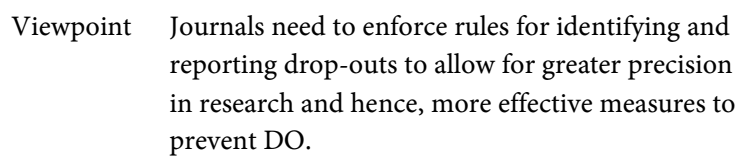

Quantitative The greatest treatment response was shown by patients who completed treatment according to plan. DO may not only be about problems with accepting a treatment plan, or a patient's resistance to therapy, but also about important interpersonal reasons, such as interpersonal aspects of the therapeutic alliance.

$\begin{array}{lll}\text { AN, BN, } & 41 & \text { Outpatient } \\ \text { EDNOS } & & \\ \text { atypical AN, } & & \\ \text { BN, } & & \\ \text { BED_- } & & \\ \text { DSM-IV } & & \\ \begin{array}{l}\text { It doesn't } \\ \text { mention }\end{array} & - & \\ \begin{array}{l}\text { diagnostic } \\ \text { criteria } \\ \text { adopted. }\end{array} & & \\ \text { AN, BN, } & 82 & \text { Outpatient } \\ \text { EDNOS } & & \text { and } \\ \text { - DSM-IV } & & \text { Inpatient } \\ & & \\ & & \end{array}$




\section{Continued}

Vandereycke Comparing the viewpoints Mixed n \& Devidt, of patients and staff about methods 2010 [11] premature termination from Belgium an inpatient treatment program for ED.
Both patients and staff were reported as important AN Restrictive 21

reasons for patients dropping out: not enough and

freedom, treatment being too difficult, and lack of purging

trust. Patients were more often satisfied with the subtypes,

therapy and therefore did not expect further $\mathrm{BN}, \mathrm{EDNOS}$

benefit in continuing the inpatient treatment. The _no reference authors propose abandoning the term "drop-out" to because of its negative connotation.

source of diagnostic criteria

Qualitative The narratives suggest deep social-psychological problems and the ambivalence of confronting or losing a relationship with food that had been both comforting and debilitating.

_It doesn't 13 mention 2011 [8] non-attendance and failure Ireland to engage with ED treatment health services.

Stein et al., Whether differential 2011 [29] treatment effects on targeted USA mechanisms of change and ED symptoms are associated with patterns of attrition in ED patients.

Q

Pingani et al., Possible risk factors for DO 2012 [17] from in-patient treatment Italy for ED. Predictive DO factors included poor educational and professional achievements, parents' divorcing, parents' history of substance abuse and difficulties in _DSM-IV TR interpersonal relationships. DO is a multifactorial phenomenon. Recognizing possible risk factors may support specific therapeutic strategies to improve treatment for ED and its outcomes.

Carter et al., Roles of individual patient 2012 [24] characteristics and Australia process-based factors in DO.

Quantitative Lowest reported weight, tendency to avoid affect, and time spent on the waiting list for treatment, were significant predictors of DO. Increased resources for ED services may reduce waiting list times, which would help reduce DO.

Pham-Scottez To identify personality et al., 2012 factors predictive of DO [14] from hospitalization. France
Quantitative There was no link between clinical features and DO, and among demographic variables, only age was associated with DO. Personality traits (Temperament and Character Inventory personality dimension and comorbid personality disorder) are significantly associated with DO from inpatient treatment for AN.

$\mathrm{AN}, \mathrm{BN}$,

Outpatient

_DSM-IV TR

Inpatient

Quantitative Participants in the MI condition were significantly AN, BN, more likely to complete intensive treatment $(69 \%$ EDNOS

completion rate) than were those in the control _DSM-IV condition $(31 \%)$. MI as a brief prelude to hospital-based treatment for ED may help improve completion rates. Further research is required to determine the precise therapeutic mechanisms of change in MI. 2013 [16] and completion rates in Canada intensive treatment for ED.
AN (DSM-IV) $64 \quad$ Inpatient

Inpatient

$\begin{array}{llll}\begin{array}{l}\text { Results suggest that drop-in access may } \\ \text { strengthen the therapeutic alliance, motivate }\end{array} & \text { AN, BN, } & 11 & \text { Outpatient } \\ \text { engagement in treatment, and reduce DO. } & \text { EDNOS } & & \\ & \text { _DSM-IV } & & \end{array}$

Clinton et al., Advantages and disadvantages Qualitative 2014 [7] of drop-in access for Sweden specialized ED services. 


\section{Continued}

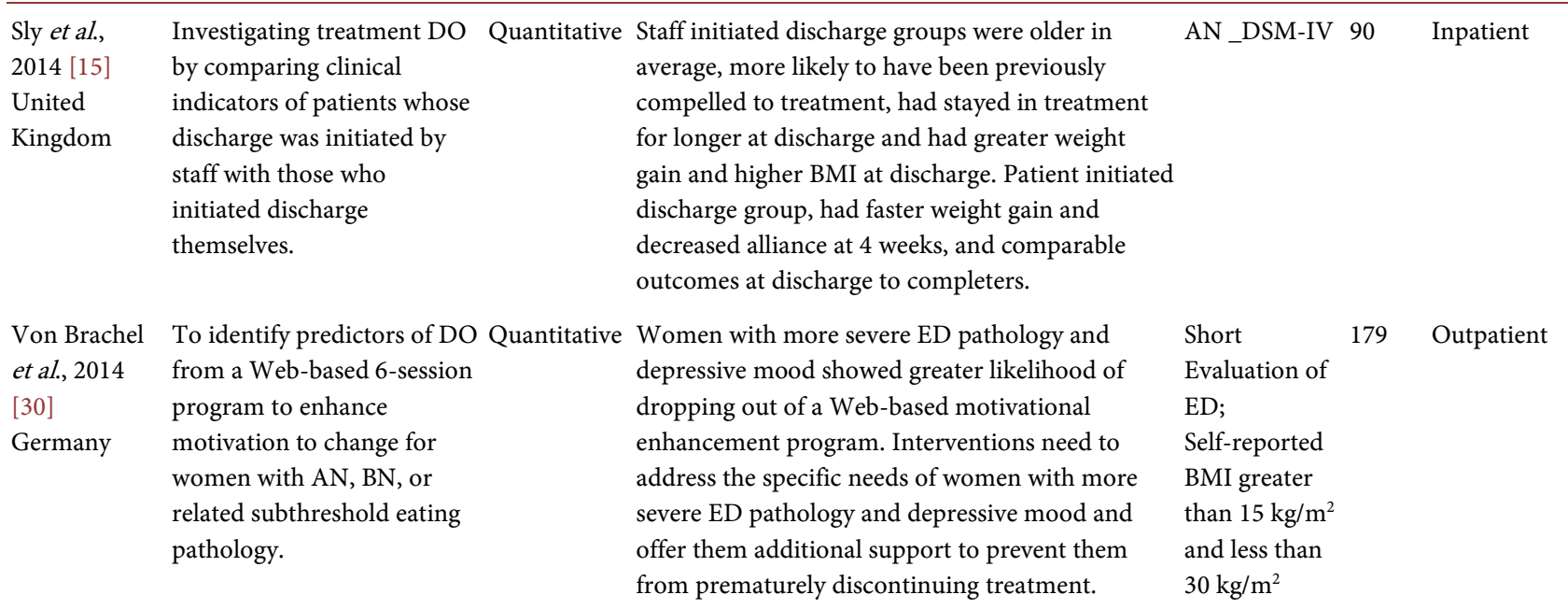

Notes: AN, Anorexia Nervosa; BN, Bulimia Nervosa; CBT; Comp: completers; Cognitive-Behavioral Therapy; DO: Dropout; DSM, Diagnostic and Statistical Manual of Mental Disorders; ED: Eating Disorders; EDNOS, Eating Disorders Not Otherwise Specified; ICD, International Classification of Diseases; MI, Motivational Interviewing; RCT, Randomized Clinical Trials.

articles adopt quantitative methods, although some (three) combine the two types.

Topics addressed: Several topics were found: 1) The relationship between narcissism and droppingout in Cognitive Behavioral Therapy (CBT) BT; 2) Different Evaluations of dropping-out by treatment teams and by patients; 3) Retrospective study searching for pre-treatment factors predicting $\mathrm{DO}$ in $\mathrm{BN}$ and atypical BN outpatients; 4) Analyses of whether differential treatment effects in the targeted mechanism of change and ED symptoms are associated with patterns of PTT during the treatment and follow-up phases in ED psychotherapy Randomized Clinical Trials (RCT); 5) A qualitative study of non-attenders in order to elicit the reasons behind non-engagement; 6) Definitions of high-risk patient profiles and the adoption of appropriate preventive strategies; 7) The roles of individual patients' characteristics and process-based factors for termination of outpatient treatment; 8) Identification of personality factors predictive of termination from hospitalization; 9) Comparisons of motivation, alliance and aspects of illness severity among groups upon admission, and comparison of outcomes upon discharge; 10) Early responses to treatment by completer groups, shifts in motivation and other aspects; 11) Attempts to identify predictors of dropping out obtained from a Web-based program in order to improve motivation in women with AN, BN or related sub-threshold eating pathologies; 12) Attempt at determining whether motivational interviewing in the form of a brief, pre-treatment intervention would be associated with higher completion rates of subsequent intensive treatment for $\mathrm{ED}$.

\section{Discussion}

\subsection{Is There a More Adequate Term Than Dropout? Or A Better Approach to the Topic?}

Bjork, Bjorck, Clinton, Sohlberg \& Norring [26] have stressed the negative con- 
notation of the term "dropout", especially in research. In the same direction, Sly [2], in a theoretical added article, points out that this "generally pejorative label" has "misdirected the research community into persisting with the examination of patient characteristics". He suggests replacing "Dropout" (DO) with "Premature Termination of Treatment" (PTT), a less pejorative and more neutral term.

The vast majority of the studies (18 out of 26) nevertheless used "dropout". The use of other terms has tended to be more frequent in recent studies, but is still rare. Two studies use "attrition" and two use "PTT". As mentioned, then, the term "dropout" is still widely used. It should be noted that the problem and the solution are not in the name itself but in how it is used in research designs, and the term's connotations in the field, including negative, or pejorative, meanings. Critical analyses [3] [5] [15] [31] of the use of the term "drop-out" have provided sufficient parameters for changing it, resulting in less biased and more accurate, comparable and consistent studies, regardless of the term used.

\subsection{Addressing Innovative Aspects-What about Experiences of Treatment?}

Campbell [3] emphasizes that "this is an area where clinicians can have a substantial impact" (p. 242). She calls attention to the need to standardize research and thus enable better comparison and replication, and she invites to evaluate the treatment models. In 2009, the same author [3] stated that retention rates worsened between 1991 and 2006 (p. 240) and expressed concern over this gloomy scenario. Other authors also stress the need for new approaches to treatment.

Several research experiences took into account the complexity of the phenomenon, studying termination based on conclusions in the literature, such as those by von Brachel et al. [30] in Germany; Weiss, Mills, Westra \& Carter [16] in Canada, and the very original experience described by Clinton, Almlöf, Lindström, Manneberg \& Vestin [7] in Sweden. Studies with "internet based" interventions [29] [30], and motivational interventions as special approaches to these patients [7] [16] [29], should also be noted.

Campbell, Waller \& Pistrang [23] noted that patients with higher scores on the Narcissistic Abuse Scale were significantly more likely to drop out of treatment, whereas no relationship was found between DO rates and higher levels of eating pathology. They concluded that such patients had "defensive personality style, seeing others as hostile and over-demanding, and presenting themselves as 'martyred'" (p. 279). This predictor for PTT should be analyzed and understood by teams because there is more evidence that termination is related to the tendency to give up, than to the eating pathology. Difficulties in interpersonal relationships analyzed by Campbell [3] suggest that this should be taken into account in research on individual treatments that seek to strengthen perseverance. It is important to stress that this information indicates the importance of building up and maintaining positive therapeutic alliances and their clinical administration. This is important because the question here is the relationship of the pa- 
tients to their treatment and the difficulties involving these personality traits. We also call attention to the importance of studying the priority of therapeutic alliances as a goal at the beginning of treatment and that without positive alliance, other goals such as gaining weight, for example, tend to be more difficult and lead to termination by the patients.

Pham-Scottez et al. [14] also aim at identifying personality factors predictive of termination, but for inpatient anorexia treatment, concluding that:

...[O]ur major finding is that personality factors (personality disorders and personality traits) contribute to the risk of dropout. Personality factors are strong clinical factors predictive of dropout. The subgroup of anorexia nervosa patients with a comorbid DSM-IV personality disorder is at significantly higher risk for dropping out, and new therapeutic tools should be applied to this subgroup to avoid this issue. (p. 812; emphasis by the authors).

\subsection{Do More Comprehensive Studies Lead Us to a Process-Oriented Perspective?}

The present review perceived a gradual trend in the research toward more process-oriented approaches to termination. Earlier studies tended to focus solely on finding predictors related to patient profiles. This procedure, combined with the implicit bias in the term "drop-out", may have led to the interpretation that some patients themselves, notably those with interpersonal difficulties and/or co-morbid personality disorders might be seen as responsible for the DO rates. There is consensus in the literature [32] [33] [34] [35] as to the high comorbidity between ED and personality disorders, and the frequent presence of these personality traits in cases without diagnosed personality disorders [32] [33] [35] [36]. It therefore seems reasonable to suppose that personality traits affecting interpersonal relationships should be considered an inherent feature of the challenge in ED treatments. Some treatment protocols take personality issues into account and consider it their responsibility to offer more effective treatment for specific ED patient profiles. This is done through programs that are processoriented and promote therapeutic alliance approaches. Such programs are probably more likely to address the current high DO rates among adults in ED treatment.

Our review detected that such approaches have been increasingly considered in more recent studies, suggesting a paradigm shift. Even when recent studies, e.g. [17] [24], focus on finding DO predictors, they tend to adopt process-based approaches that target the phenomenon of PTT in a broader way. The same is true of articles that use the term "attrition" [29], a word that tends to include other variables besides individual "resistance to treatment". Considering inherent features of ED patients as "resistance" seems to lead to less efficient treatment approaches. At the same time, this stance could excuse treatment teams from taking responsibility for considering such traits as an essential part of the 
psychopathology that should be addressed as the first step of treatment. This paradigm shift could open possibilities for investigating a broader range of factors, such as treatment protocol designs. Such attempts to reduce biases are essential when seen in the light of the first generation of studies in the field. The change, for example, allows treatment teams to consider implementing motivational strategies tailored to the needs of significant portions of patients who are most likely to dropout. At the same time, the change brings up the question of the role of the teams that are carrying out the treatment.

\subsection{Overcoming the Dropout Paradigm}

The paradigm shift allowed for different interpretations of DO in more recent studies, in alignment with the view that the earliest use of the term "dropout" in research, may have been a misuse [2] [3] [5]. Mahon [5] criticizes the tendency to identify "dropout" with a patient-characteristic profile. The follow-up study by Bjork et al. [26], was a landmark in signaling that termination of treatment need not always be taken in a negative sense, nor as a pathologic reaction.

For instance, these authors surprisingly observed that at intake, so-called "dropouts" had a less negative self-image and scored significantly higher than other patients on the self-emancipation cluster of the structural analysis of social behavior (SASB), used to evaluate self-image. These patients also showed lower intake levels of self-blame and self-hatred than the completers.

In the same vein, Vandereycken \& Vansteenkiste [18] and Zeeck \& Herzog [12] question "dropout" as a synonym for poor compliance or for failures in the treatment. These latter authors found that depressive patients are unlikely to drop out and that most patients who do drop out seek other services within three months.

We consider that a paradigm shift has been taking place over the last ten years, and it represents a welcome evolution in the area. This shift can be defined as a change in focus from the search for predictors of DO to factors most frequently involved in PTT. This has been critically discussed in several viewpoint articles by Sly [2] (not included in the present review, but added as an additional reference relevant to the discussion), Campbell [3], and in the reviews of Mahon [5] and Wallier et al. [4]. In addition, overcoming this paradigm means that the narrow and reductionist view that sees DO as resistance to treatment by patients is also shifting. We can now ask what challenges remain, or in what direction can advances in research and clinical practice for eating disorders be made, considering the findings regard to PTT?

\subsection{What Is the Role of Qualitative Research?}

We propose this question in order to inquire into the contribution of qualitative research toward advances in dealing with PTT for ED. The basic aspect is: How can in-depth qualitative research contribute with this issue? Even though qualitative studies have been suggested and encouraged by many authors [3] [5] [9] 
[11] [19] [21], such studies are still rare, such as Eivors, Button, Warner \& Turner [37], Sheridan \& McArdle [38] and Thapliyal, Mitchison and Hay [39].

We found only two studies [7] [8] that take a purely in-depth qualitative approach, despite the numerous recommendations to employ qualitative methods. Mahon [5] states that:

Qualitative, interview-based research will be central to clarifying the causes of dropping out. Although asking former patients why they have left seems an obvious means of learning about dropping out, it has not often been done [...] Quantitative studies, however, show there are no differences between drop-outs and completers on these variables, so these patients might be giving a "polite" reason for leaving. Indeed, qualitative studies have shown drop-outs to be affected by difficulties in communicating with their therapists or in feeling unsafe with or intimidated by them (p. 211).

In the same direction, Pham-Scottez et al., 2012 [14] call for further "prospective studies with rigorous qualitative methodology [...] to better understand premature termination of hospitalization and DO from treatment for ED, in general, and to prevent it more efficiently" (p. 812).

In the field of health science research, clinical trials, particularly of the randomized controlled type, are considered the gold standard for producing reliable evidence. Hence the rarity of qualitative studies. Nonetheless, the difficulty of securing large enough samples to enable randomized controlled trials is well-known to ED researchers. Ironically, this difficulty is due, among other factors, to the high rates of treatment DO. In view of recent indications of paradigm shift and the surprising discovery of "positive dropout" [12] [18] [26], this review suggests that qualitative research may be a powerful resource in bringing to the fore unforeseen issues involved in PTT for ED and the formulation of better hypotheses to be investigated through quantitative research that will hopefully contribute to advances in this area.

\subsection{Therapeutic Alliance and Relationships-Accessory Management or Treatment Itself?}

This review has also identified the importance of the role of the therapeutic alliance in PTT and more specifically, the flexibility as a part of treatment and its management strategies. This may promote the management of therapeutic alliances, as suggested by Vandereycken and Vansteenkiste [18], who found that enhancing patient's autonomy and volition by giving them a personal choice at the beginning of hospitalization enhanced patients' autonomy and willingness to accept treatment, thus significantly reducing DO during the first weeks of inpatient treatment (p. 812). This experience also shows that a lenient approach that expands the patients' degree of choice in treatment can aid in reducing DO rates. To quote Vandereycken and Vansteenkiste [18] (p. 182):

"Although drop-out is generally considered as a signal of poor compliance 
and/or, treatment failure, this not necessarily needs to be the case. Patients can decide to stop treatment for various reasons, including defiance against external authority figures that force them into treatment, a lack of confidence to make therapeutic change, or because the treatment program does not meet the patients' needs or expectations".

In the same direction, Mahon [5] notes that softer and more flexible approaches can increase adherence and reduce DO. The conclusion is that flexibility should be considered an essential dimension of treatment for ED.

Furthermore, Clinton [20] has noted that "dropouts were characterised by high degrees of patient-therapist dissimilarity of expectations concerning the efficacy of psychodynamic interventions" (p. 34). Pointing out that dropout may increase when patients and therapists have substantially different notions of the value of insight-related interventions, Clinton [20] also recommends to discuss expectations related to treatment with the patients from the outset, focusing on particular areas of discrepancy to limit potential drop-out, supporting the relevance of greater flexibility in treatment settings.

Bandini et al. [25] suggest "the need for effective therapeutic guidelines, which take DO into account. It is important to facilitate the cooperation of the patient from the first session and during the whole treatment, mediated by a strong motivation" (p. 182), highlighting the role of therapist in treatment management in these interventions. It might be important to stress that this type of approach includes questions related to the clinical management of the interpersonal difficulties of ED patients.

Almost ten years ago, after highlighting personality factors such as impulsivity, Wallier et al. [4] concluded that future research should consider the therapeutic alliance of patients and their families in the prediction of dropout. However, this present review shows minor advancement in this sense. Wallier also highlights the need "to tailor treatment for those patients at risk for dropping out, with the goal of avoiding the less favorable outcome that such patients may experience" (p. 646). Beyond prioritizing strategies to increase compliance at admission, the clearest and most potent role of better therapeutic alliance is to treat and clinically manage ED patients' difficulties in the field of interpersonal relationships.

The frequent surfacing of interpersonal difficulties inevitably affects patients' relationship with therapists and treatment teams, making the relationship fragile and more likely to break up. Furthermore, establishing weight restoration as the primary treatment goal tends to result in termination of treatment if it is experienced as unbearable to patients. In this respect, it might be interesting to examine once again the meanings of the terms involved. "Dropout" in the sense of an individual withdrawing from a relationship, implies losing a sense of attachment, falling out of the loop when something becomes unbearable. In contrast, "attrition" means "A wearing down or weakening of resistance, especially while a result of continuous pressure or harassment" [40]. 
Therefore, a therapeutic alliance should be considered treatment and be defined as a goal from the start. The present review indicates that the issue of ruptures implied in PTT should be part of the psychopathology involved, in order to be taken as a goal of the treatment. Therefore, rupture is a relevant psychological issue. If DO is to be addressed, patients must be offered proper support by both treatment protocols and treatment teams, and the therapeutic alliance must be adequately managed.

The intense fear of gaining weight is a core symptom in ED. The present review suggests it also plays an important role in difficulties in the therapeutic alliance in contexts where interpersonal relationship difficulties have already taken on a major dimension of the psychopathology involved. Perhaps it is time to consider treatment approaches that can offer better options in assisting patients to overcome their fears and interpersonal difficulties. It is possible that medically-centered approaches, focused on restoration of physical health parameters such as weight, can be felt as coercive by such patients, due to their emotional frailties, personality traits and difficulties in the field of interpersonal relationship. PTT is recognized as a multifaceted and complex phenomenon as it should be faced as a clinical problem in the area of interpersonal relationships. PTT remains a probable outcome, as we know, and we still seem unable to prevent it in many cases.

\section{Closing Remarks}

Research on premature termination of treatment for eating disorders has changed in several ways, as overcoming methodological problems, going deeper and becoming more comprehensive. In addition, further qualitative studies should be carried out to investigate the meanings of terminations. This concern is not new, but neither has it evolved very far. As part of the solution, we suggest using the COREQ reporting [41].

We also suggest analyzing the financial costs of high rates of treatment termination, improved and novel treatment approaches. In this respect, the fundamental role of therapeutic alliance and treatment teams must be stressed for managing a central feature of psychological issues related to ED, namely, difficulties in personal relationships. Tailored approaches are needed for potential terminators that will consider the likelihood of their dropping-out due to issues related to their therapeutic alliance. Therefore, it might be worthwhile to invest in the development of knowledge and practices about how to manage therapeutic alliances. Possible paths to recovery must be studied more deeply in order to develop motivational strategies for these patients.

We also propose the following questions: 1) Are multidisciplinary treatment teams ready to change their practices once they become aware of the present research results and their clinical implications? 2) Are professionals receptive to addressing the inner functioning of the teams? In this regard, we recommend the regular practice of clinical supervision to back up teams that deal with daily 
therapeutic relationships. The objective is to enable professionals to listen better to patients and manage the interpersonal difficulties of those with ED.

This study shows some limitations, including: 1) The absence of a standardized definition of "dropout", which has prevented the presentation of a systematic review that could add more evidence to the critical analysis of the findings; 2) The failure to include search terms such as family factors, personality factors, impulsivity, interpersonal relationship, interpersonal aspects and therapeutic alliance. We strongly recommend further research based on these keywords.

\section{Acknowledgements}

The authors gratefully acknowledge the financial support of grants from CAPES and FAPESP (Support Research FAPESP 2011/20469-8) - during the first author's Master's Degree in which she started to investigate the issue of DO in ED, and conducted a former review. They are grateful to LCQR, as well as to Terrence Hill for the English language review and also to Monica F. Caron and José Nabuco Galvão de Barros Filho for their kind help in reviewing.

\section{Ethical Approval}

This article does not contain any studies with human participants performed by any of the authors.

\section{Conflicts of Interest}

The authors declare no conflicts of interest regarding the publication of this paper.

\section{References}

[1] Vandereycken, W. and Pierloot, R. (1983) Drop-Out during In-Patient Treatment of Anorexia Nervosa: A Clinical Study of 133 Patients. British Journal of Clinical Psychology, 56, 145-156. https://doi.org/10.1111/j.2044-8341.1983.tb01542.x

[2] Sly, R. (2009) What's in a Name? Classifying "the Dropout" from Treatment for Anorexia Nervosain. European Eating Disorders Review, 17, 405-407. https://doi.org/10.1002/erv.964

[3] Campbell, M. (2009) Drop-Out from Treatment for Eating Disorders: A Problem for Clinicians and Researchers. European Eating Disorders Review, 17, 239-242. https://doi.org/10.1002/erv.934

[4] Wallier, J., Vibert, S., Berthoz, S., Huas, C., Hubert, T. and Godart, N. (2009) Dropout from Inpatient Treatment for Anorexia Nervosa: Critical Review of the Literature. International Journal of Eating Disorders, 42, 636-647. https://doi.org/10.1002/eat.20609

[5] Mahon, J. (2000) Dropping out from Psychological Treatment for Eating Disorders: What Are the Issues? European Eating Disorders Review, 8, 198-216. https://doi.org/10.1002/(SICI)1099-0968(200005)8:3<198::AID-ERV356>3.0.CO;2-3

[6] Seidinger-Leibovitz, F.M., Rodrigues, L., Garcia Júnior, C. and Vieira, C.M. (2016) Dropout in Treatment for Anorexia Nervosa and Bulimia: A Critical Review. Rev Interface, 11, 120-137. 
[7] Clinton, D., Almlöf, L., Lindström, S., Manneberg, M. and Vestin, L. (2014) Drop-In Access to Specialist Services for Eating Disorders: A Qualitative Study of Patient Experiences. Eating Disorders, 22, 279-291. https://doi.org/10.1080/10640266.2014.912553

[8] Leavey, G., Vallianatou, C., Johnson-Sabine, E., Rae, S. and Gunputh, V. (2011) Psychosocial Barriers to Engagement with an Eating Disorder Service: A Qualitative Analysis of Failure to Attend. Eating Disorders, 19, 425-440. https://doi.org/10.1080/10640266.2011.609096

[9] Surgenor, L.J., Maguire, S. and Beumont, P.J.V. (2004) Drop-Out from Inpatient Treatment for Anorexia Nervosa: Can Risk Factors Be Identified at Point of Admission? European Eating Disorders Review, 12, 94-100. https://doi.org/10.1002/erv.539

[10] Zanetti, T., Favaro, L.C.A. and Santonastaso, P. (2005) Middle Term Outcome in Anorexia Nervosa Outpatients Who Dropped Out from Therapy. Rivista di Psichiatria, 40, 149-155.

[11] Vandereycken, W. and Devidt, K. (2010) Dropping Out from a Specialized Inpatient Treatment for Eating Disorders: The Perception of Patients and Staff. Eating Disorders, 18, 140-147. https://doi.org/10.1080/10640260903585557

[12] Zeeck, A. and Herzog, T. (2000) Behandlungsabbrüche bei der stationären Behandlung der Anorexia nervosa. Der Nervenarzt, 71, 565-572. https://doi.org/10.1007/s001150050627

[13] Zeeck, A., Hartmann, A., Buchholz, C. and Herzog, T. (2005) Drop Outs from In-Patient Treatment of Anorexia Nervosa. Acta Psychiatrica Scandinavica, 111, 29-37. https://doi.org/10.1111/j.1600-0447.2004.00378.x

[14] Pham-Scottez, A., Huas, C., Perez-Diaz, F., Nordon, C., Divac, S., Dardennes, R., Speranza, M. and Rouillon, F. (2012) Why Do People with Eating Disorders Drop Out from Inpatient Treatment: The Role of Personality Factors. The Journal of Nervous and Mental Disease, 200, 807-813. https://doi.org/10.1097/NMD.0b013e318266bbba

[15] Sly, R., Mountford, V.A., Morgan, J.F. and Lacey, J.H. (2014) Premature Termination of Treatment for Anorexia Nervosa: Differences between Patient-Initiated and Staff-Initiated Discharge. The International Journal of Eating Disorders, 47, 40-46. https://doi.org/10.1002/eat.22190

[16] Weiss, C.V., Mills, J.S., Westra, H.A. and Carter, J.C. (2013) A Preliminary Study of Motivational Interviewing as a Prelude to Intensive Treatment for an Eating Disorder. Journal of Eating Disorders, 1, Article No. 34. https://doi.org/10.1186/2050-2974-1-34

[17] Pingani, L., Catellani, S., Arnone, F., De Bernardis, E., Vinci, V., Ziosi, G., Turrini, G., Rigatelli, M. and Ferrari, S. (2012) Predictors of Dropout from In-Patient Treatment of Eating Disorders: An Italian Experience. Eating and Weight Disorders, 17, e290-e297. https://doi.org/10.1007/BF03325140

[18] Vandereycken, W. and Vansteenkiste, M. (2009) Let Eating Disorder Patients Decide Providing Choice May Reduce Early Drop-Out from Inpatient Treatment. $E u$ ropean Eating Disorders Review, 17, 177-183. https://doi.org/10.1002/erv.917

[19] Masson, P.C., Perlman, C.M., Ross, S.A. and Gates, A.L. (2007) Premature Termination of Treatment in an Inpatient Eating Disorder Program. European Eating Disorders Review, 15, 275-282. https://doi.org/10.1002/erv.762

[20] Clinton, D. (1996) Why Do Eating Disorder Patients Drop Out? Psychotherapy and Psychosomatics, 65, 29-35. https://doi.org/10.1159/000289028 
[21] Mahon, J., Winston, A.P., Palmer, R.L. and Harvey, P.K. (2001) Do Broken Relationships in Childhood Relate to Bulimic Women Breaking off Psychotherapy in Adulthood? International Journal of Eating Disorders, 29, 139-149. https://doi.org/10.1002/1098-108X(200103)29:2<139::AID-EAT1003>3.0.CO;2-I

[22] Peake, K.J., Limbert, C. and Whitehead, L. (2005) Gone, but Not Forgotten: An Examination of the Factors Associated with Dropping Out from Treatment of Eating Disorders. European Eating Disorders Review, 13, 330-337. https://doi.org/10.1002/erv.645

[23] Campbell, M.A., Waller, G. and Pistrang, N. (2009) The Impact of Narcissism on Drop-Out from Cognitive-Behavioral Therapy for the Eating Disorders: A Pilot Study. The Journal of Nervous and Mental Disease, 197, 278-281. https://doi.org/10.1097/NMD.0b013e31819dc150

[24] Carter, O., Pannekoek, L., Fursland, A., Allen, K.L., Lampard, A.M. and Byrne, S.M. (2012) Increased Wait-List Time Predicts Dropout from Outpatient Enhanced Cognitive Behaviour Therapy (CBT-E) for Eating Disorders. Behaviour Research and Therapy, 50, 487-492. https://doi.org/10.1016/j.brat.2012.03.003

[25] Bandini, S., Antonelli, G., Moretti, P., Pampanelli, S., Quartesan, R. and Perriello, G. (2006) Factors Affecting Dropout in Outpatient Eating Disorder Treatment. Eating and Weight Disorders, 11, 179-184. https://doi.org/10.1007/BF03327569

[26] Bjork, T., Bjorck, C., Clinton, D., Sohlberg, S. and Norring, C. (2009) What Happened to the Ones Who Dropped Out? Outcome in Eating Disorder Patients Who Complete or Prematurely Terminate Treatment. European Eating Disorders Review, 17, 109-119. https://doi.org/10.1002/erv.911

[27] Fassino, S., Abbate-Daga, G., Pierò, A., Leombruni, P. and Rovera, G.G. (2003) Dropout from Brief Psychotherapy within a Combination Treatment in Bulimia Nervosa: Role of Personality and Anger. Psychotherapy and Psychosomatics, 72, 203-210. https://doi.org/10.1159/000070784

[28] Swan-Kremeier, L.A., Mitchell, J.E., Twardowski, T., Lancaster, K. and Crosby, R.D. (2005) Travel Distance and Attrition in Outpatient Eating Disorders Treatment. International Journal of Eating Disorders, 38, 367-370. https://doi.org/10.1002/eat.20192

[29] Stein, K.F., Wing, J., Lewis, A. and Raghunatha, T. (2011) An Eating Disorder Randomized Clinical Trial \& Attrition: Profiles \& Determinants of Dropout. International Journal of Eating Disorders, 44, 356-368. https://doi.org/10.1002/eat.20800

[30] Von Brachel, R., Hötzel, K., Hirschfeld, G., Rieger, E., Schmidt, U., Kosfelder, J., Hechler, T., Schulte, D. and Vocks, S. (2014) Internet-Based Motivation Program for Women with Eating Disorders: Eating Disorder Pathology and Depressive Mood Predict Dropout. Journal of Medical Internet Research, 16, e92. https://doi.org/10.2196/jmir.3104

[31] De Jong, H., Broadbent, H. and Schmidt, U. (2012) A Systematic Review of Dropout from Treatment in Outpatients with Anorexia Nervosa. International Journal of Eating Disorders, 45, 635-647. https://doi.org/10.1002/eat.20956

[32] Connan, F., Dhokia, R., Haslam, M., Mordant, N., Morgan, G., Pandya, C. and Waller, G. (2009) Personality Disorder Cognitions in the Eating Disorders. Behaviour Research and Therapy, 47, 77-82. https://doi.org/10.1016/j.brat.2008.10.010

[33] Gabriel, C. and Waller, G. (2014) Personality Disorder Cognitions in the Eating Disorders. The Journal of Nervous and Mental Disease, 202, 172-176. https://doi.org/10.1097/NMD.0000000000000088

[34] Magallón-Neri, E., González, E., Canalda, G., Forns, M., De La Fuente, J.E., 
Martínez, E. and Castro-Fornieles, J. (2014) Prevalence and Severity of Categorical and Dimensional Personality Disorders in Adolescents with Eating Disorders. European Eating Disorders Review, 22, 176-184. https://doi.org/10.1002/erv.2268

[35] Waller, G., Ormonde, L. and Kuteyi, Y. (2013) Clusters of Personality Disorder Cognitions in the Eating Disorders. European Eating Disorders Review, 21, 28-31. https://doi.org/10.1002/erv.2209

[36] Gaudios, S. and Dakanalis, A. (2017) Personality and Eating and Weight Disorders: An Open Research Challenge. Eating and Weight Disorders, 23, 143-147. https://doi.org/10.1007/s40519-017-0463-0

[37] Eivors, A., Button, E., Warner, S. and Turner, K. (2003) Understanding the Experience of Drop-Out from Treatment for Anorexia Nervosa. European Eating Disorders Review, 11, 90-107. https://doi.org/10.1002/erv.492

[38] Sheridan, G. and McArdle, S. (2016) Exploring Patients' Experiences of Eating Disorder Treatment Services from a Motivational Perspective. Qualitative Health Research, 26, 1988-1997. https://doi.org/10.1177/1049732315591982

[39] Thapliyal, P., Mitchison, D. and Hay, P. (2017) Insights into the Experiences of Treatment for an Eating Disorder in Men: A Qualitative Study of Autobiographies. Behavioral Sciences, 7, 38. https://doi.org/10.3390/bs7020038

[40] (2018). https://www.wordreference.com/definition/attrition

[41] Tong, A., Sainsbury, P. and Craig, J. (2007) Consolidated Criteria for Reporting Qualitative Research (COREQ): A 32-Item Checklist for Interviews. International Journal for Quality in Health Care, 19, 349-357.

https://doi.org/10.1093/intqhc/mzm042 